\title{
Impact of Covid 19 Pandemic on Surgical Outcomes, A Single Center Experience
}

\author{
ZAHRAA FUTOOH, M.D.*; NEHAL FAROUK, M.D.** and DALIA GAD, M.D.*** \\ The Departments of General Surgery*, Vascular Surgery** and Pediatric Surgery***, Faculty of Medicine for Girls, \\ Al-Azhar University
}

\begin{abstract}
Background: Covid 19 is global pandemic that affected millions of people worldwide causing extreme limitations in hospital admission for non-emergency surgical diseases.

Aim of Study: To assess the effect of Covid 19 infection on surgerical outcomes (surgery related complications, ICU admission and mortality rates.

Patients and Methods: Data of all patients admitted to Al-Zahraa University Hospital in the Departments of General, Vascular, and Pediatric Surgeries was collected regarding age, sex, type of operation, associated risk factors, infection by Covid 19, surgery related complications, ICU admission, mortality, also postponed patients.

Results: Of 784 patients in three departments 54 patients were infected with Covid 19 (6.88\%), significant increase in surgery related morbidity in Covid infected patients with a $p$-value $<0.001$ more at vascular and pediatric patients in comparison to general surgery patients with $p$-value 0.045 respectively. Also significant increase in ICU admission, need for respiratory aid and mortality rate with $p 0.044$, this increased risk is more with presence of ischemic heart disease IHD $p=0.014,0.07$ respectively and congenital heart disease $p=0.018$.
\end{abstract}

Conclusion: Covid 19 affects surgical patients by great restriction of elective procedures, delayed scheduling even worse surgical outcomes.

Key Words: Covid-19 - Surgical outcomes - Surgery related complication.

\section{Introduction}

IN December 2019, a new strain of SARScoronavirus, initially named 2019 coronavirus (2019-nCoV) and manifested by Severe Acute Respiratory Syndrome Coronavirus 2 (SARS-CoV2), emerged in Wuhan, China [1].

It rapidly spread as an outbreak there. And the World Health Organization (WHO) announced this

Correspondence to: Dr. Zahraa Futooh, E-Mail: Zahraa futooh@azhar.edu.eg on January 22, 2020. On the 23 rd of January, it was announced that the outbreak constituted a public health emergency of international concern [2].

WHO designated the disease as Coronavirus Disease 2019 (COVID-19) and the causative agent with Severe Acute Respiratory Syndrome Coronavirus 2 (SARS-CoV-2) in February 2020. Few weeks later, the virus spread was recorded worldwide and was announced as a pandemic by WHO in March 11, 2020. As of 16 August 2020, the infection had spread worldwide, with $21,294,845$ confirmed cases and 761,779 death [3]

Global spread included Egypt, and the first case was recorded in Egypt on February 14, 2020 the total number of confirmed cases on May 1,2020, was 5895 , with case fatality rate of $6.9 \%$. And to up 6 February 2021, there have been 168,597 confirmed cases of COVID-19 with 9,560 deaths.

During the COVID-19 pandemic, all governmental and university hospitals have stopped the service of elective surgeries with increasing number of patients needing urgent and semi-urgent procedures. After regression of the $1{ }^{\text {st }}$ wave the need for regaining activity was strong, and as surgical procedures may place clinicians at a particularly high risk when caring for infected patients, this required certain arrangements for fear of further spread of the virus to the patients and staff.

Thus, it is critically important to know how COVID-19 affects surgical outcomes, thus, effective personal protective procedures and cautions should be taken to prevent medical staff from COVID-19 infection [4].

Surgical stress may impair cell-mediated immunity to reduce the resistance to viruses. COVID- 
19 may complicate the post-operative course to increase the lenghth of stay, delay the wound healing, increase morbidity and even mortality of operative patients [5].

At present, little is known about the clinical characteristics and out-comes of operative patients with COVID-19 during the perioperative period [6]. The aim of this study to describe the clinical outcomes, surgical mortality and complication rates in surgical patients with COVID-19.

\section{Patients and Methods}

We collected data of all patients who were admitted to General Surgery, Vascular and Pediatric Surgery Departments in the period from beginning of lockdown in Egypt on the 15 th of March 2020 till the end of January 2021 the collected data included the total count of patients operated upon in the three departments and the surgery related complications in total. Data collected related to Covid infected patients included age, associated disease which can affect prognosis which are Hypertension (HTN), diabetes, Ischemic Heart Disease (IHD) and also congenital heart disease in pediatric patients, degree of affection, surgery related complications, ICU admission, need for respiratory aid and mortality of each case.

Grade of affection: We divided patients as for grade of Covid 19 affection.

Table (1): Grading of affection.

\begin{tabular}{ll}
\hline Asymptomatic & Ia \\
Mild symptoms need no extra treatment & Ib \\
Mild symptoms need extra treatment & II \\
Moderate symptoms & IIIa \\
Moderate symptoms need intervention & IIIb \\
ICU admission & IVa \\
Mechanical ventilation & IVb \\
Death & V \\
\hline
\end{tabular}

We also included patients who were postponed because of Covid 19 affection as they were given another date and rescheduled for an operation after being free of symptoms.

Patients were diagnosed as Covid 19 infection through either PCR positive for SARS-Cov. Virus from a nasal swab or though having symptoms suggestive for Covid 19 infection confirmed by blood tests and confirmatory CT scan on chest has the catachrestic ground glass patches even in asymptomatic patients.

Also we tried to find a relationship between Covid infection and surgery related complication, ICU admission, need for respiratory support and mortality rate and if that has a relationship with patients age groups.

\section{Statistical method:}

Data were coded and entered using the Statistical Package for the Social Sciences (SPSS) version 26 (IBM Corp., Armonk, NY, USA). Data was summarized using mean, standard deviation, median, minimum and maximum in quantitative data and using frequency (count) and relative frequency (percentage) for categorical data. Comparisons between quantitative variables were done using the non-parametric Mann-Whitney test [7]. For comparing categorical data, Chi square $\left(\mathrm{X}^{2}\right)$ test was performed. Exact test was used instead when the expected frequency is less than 5 [8] $p$-values less than 0.05 were considered as statistically significant.

\section{Results}

Of 784 patients admitted there were 469 general surgical cases (59.8\%), 132 vascular sugery cases $(16.8 \%)$ and 181 pediatric surgery cases $23.3 \%$, 54 patients were diagnosed as Covid 19 infection which are $(6.88 \%)$ of all patients and; 24 patients in surgery $(3.01 \%) 11$ in vascular surgery $(1.4 \%)$ and 19 patients in pediatric surgery $(2.4 \%)$, of all patients (Table 2).

Of the 54 patients who had Covid 19 infection only $15(27.77 \%)$ patients were emergency patients and the rest $39(72 \%)$ cases were elective patients $20(37 \%)$ patients were diagnosed pre-operatively by CT findings and $\mathrm{CBC}$ with a picture of lymphopenia and they were postponed and reoperated after passing the infection except 3 patients were diagnosed by positive PCR nasal smear of Cov-19.

\section{Associated risk factors:}

Of the 54 Covid infected patients $9(16.7 \%)$ patients were hypertensive $10(18.5 \%)$ patients were diabetic patients, $6(11 \%)$ patients have ischemic heart disease and 4 patients had COPD $(7.4 \%)$, in the pediatric patients only $3(15.7 \%)$ of pediatric patients have congenital heart disease.

Of all Covid patients there was 19 patients grade I affection, 4 patients grade II affection, 18 patients grade III, 8 patients grade IV and six patients passed away of Covid 19 complications related to surgery. In Covid affected patients there were $28(51.9 \%)$ patients who have complications related to surgery in spite of being Covid patients 10 out of 24 in General Surgery (41.7\%), 7 out of 11 in Vascular Surgery patients $(63.6 \%)$ and 11 out of 19 in pediatric surgery (57\%) Table (4). 
ICU admission: There was 11 out of $54(29.5 \%)$ covid affected patients were admitted to the ICU 5 (20\% of covid infected patients) in General Surgery, 5 (45\%) in Vascular Surgery and 6 (31.6\%) Pediatric Surgery patients.

However, need for respiratory aid was done for 19 patients of all Covid affected patients (35.2\%) of all patients.

11 patients have died (1.4\%) of all surgery patients and 6 of them were covid patients which is $(11.1 \%$ of ) all infected patients 1 (2.27) from General Surgery Department, 3 (6.8\%) from Vascular Surgery and $2(4.54 \%)$ of all mortalities 6 of 11 patients were because of covid $19(54.5 \%)$ of mortality.

Statistical findings: There was significant increase in rate of covid infection among vascular and pediatric surgery patients in comparison to general surgery patients $p$-value 0.045 .

Significant increase in surgery related complications in Covid infected patients in comparison to non-infected patients $p$-value 0.001 .

Significant increase in mortality rate in Covid infected patients in comparison to Covid non infected patients $p$-value $<0.001$ (Table 6).

Also found significant increase in both complications related to surgery and death rate in emergency cases in comparison to elective cases $p$ values: 0.001 and 0.044 respectively (Table 7).

But no significant relationship between surgery related complications and presence of associated chronic disease in Covid infected patients.

There was no significant relationship between ICU admission in Covid infected patients with presence of diabetes, hypertention, COPD but there was significant relationship between ICU admission and also mortality rate in ischemic heart disease $p$-value 0.007 and 0.014 . respectively (Tables 8,9 ).

In pediatric patients we found no relationship between presence of congenital heart disease and rate of surgery related complications, ICU admission but there was a significant increase of mortality rate in pediatric patients who had congenital heart disease Tables $(10,11,12)$.

Table (2): Description of COVID in each department

\begin{tabular}{|c|c|c|c|c|c|c|}
\hline & \multicolumn{2}{|c|}{ General } & \multicolumn{2}{|c|}{ Vascular } & \multicolumn{2}{|c|}{ Pediatric } \\
\hline & Count & $\%$ & Count & $\%$ & Count & $\%$ \\
\hline \multicolumn{7}{|l|}{ Sex: } \\
\hline Male & 14 & 58.3 & 6 & 54.5 & 11 & 57.9 \\
\hline Female & 10 & 41.7 & 5 & 45.5 & 8 & 42.1 \\
\hline \multicolumn{7}{|l|}{ Way of diagnosis: } \\
\hline PCR & 2 & 8.3 & 1 & 9.1 & 0 & 0.0 \\
\hline $\mathrm{CT}$ & 22 & 91.7 & 10 & 90.9 & 2 & 10.5 \\
\hline $\mathrm{CBC}+\mathrm{CT}$ & 0 & 0.0 & 0 & 0.0 & 4 & 21.1 \\
\hline $\mathrm{CBC}+\mathrm{CT}+\mathrm{CRP}$ & 0 & 0.0 & 0 & 0.0 & 13 & 68.4 \\
\hline \multicolumn{7}{|l|}{ Emergency or elective: } \\
\hline Emergency & 6 & 25.0 & 3 & 27.3 & 6 & 31.6 \\
\hline Elective & 18 & 75.0 & 8 & 72.7 & 13 & 68.4 \\
\hline \multicolumn{7}{|l|}{ Timing of diagnosis: } \\
\hline Pre & 12 & 50.0 & 4 & 36.4 & 11 & 57.9 \\
\hline Post & 12 & 50.0 & 7 & 63.6 & 8 & 42.1 \\
\hline \multicolumn{7}{|l|}{ Postponed: } \\
\hline Yes & 10 & 41.7 & 4 & 36.4 & 6 & 31.6 \\
\hline No & 14 & 58.3 & 7 & 63.6 & 13 & 68.4 \\
\hline \multicolumn{7}{|l|}{$H T N:$} \\
\hline Yes & 3 & 12.5 & 6 & 54.5 & 0 & 0.0 \\
\hline No & 21 & 87.5 & 5 & 45.5 & 19 & 100.0 \\
\hline \multicolumn{7}{|l|}{ Diabetic: } \\
\hline Yes & 4 & 16.7 & 6 & 54.5 & 0 & 0.0 \\
\hline No & 20 & 83.3 & 5 & 45.5 & 19 & 100.0 \\
\hline \multicolumn{7}{|l|}{$I H D:$} \\
\hline Yes & 2 & 8.3 & 4 & 36.4 & 0 & 0.0 \\
\hline No & 22 & 91.7 & 7 & 63.6 & 19 & 100.0 \\
\hline \multicolumn{7}{|l|}{ COPD: } \\
\hline Yes & 1 & 4.2 & 3 & 27.3 & 0 & 0.0 \\
\hline No & 23 & 95.8 & 8 & 72.7 & 19 & 100.0 \\
\hline
\end{tabular}

Table (3): Procedures done for Covid 19 patients.

\begin{tabular}{|c|c|c|c|c|c|}
\hline \multicolumn{2}{|l|}{ General surgery } & \multicolumn{2}{|l|}{ Vascular surgery } & \multicolumn{2}{|l|}{ Pediatric surgery } \\
\hline Procedure & $\begin{array}{c}\text { No. of } \\
\text { patients }\end{array}$ & Procedure & $\begin{array}{c}\text { No. of } \\
\text { patients }\end{array}$ & Procedure & $\begin{array}{l}\text { No. of } \\
\text { patients }\end{array}$ \\
\hline $\begin{array}{l}\text { - Hernia } \\
\text { - Cholecystectomy } \\
\text { - Thyroidectomy } \\
\text { - Appendectomy } \\
\text { - (Exploration) perforated viscous } \\
\text { and intestinal obstruction } \\
\text { - Hydrocele } \\
\text { - Back lipoma } \\
\text { - Nancer head pancreas } \\
\text { - Anal }\end{array}$ & $\begin{array}{l}4 \\
6 \\
2 \\
3 \\
3 \\
1 \\
1 \\
1 \\
1 \\
1 \\
2\end{array}$ & $\begin{array}{l}\text { - Femoro pop by pass } \\
\text { - Ilio pop by pass } \\
\text { - Arterio venous fistula } \\
\text { - Primary repair of aneurysm } \\
\text { - Endovascular surgery } \\
\text { - Primary major limb } \\
\text { amputation } \\
\text { - High tie and stripping }\end{array}$ & $\begin{array}{l}2 \\
1 \\
2 \\
2 \\
2 \\
1 \\
1 \\
1\end{array}$ & $\begin{array}{l}\text { - Inguinal hernia, hydrocel } \\
\text { - Umbilical hernia } \\
\text { - Hypospadias } \\
\text { - Anoplasty } \\
\text { - Hirschsprung disease } \\
\text { - Appendectomy } \\
\text { - Abdominal exploration } \\
\text { - Excision of infantile } \\
\text { haemangioma }\end{array}$ & $\begin{array}{l}7 \\
3 \\
3 \\
3 \\
1 \\
1 \\
2 \\
1 \\
1\end{array}$ \\
\hline
\end{tabular}


Table (4): Grade of affection of patients from each department and outcomes.
Table (6): Mortality rate in COVID in comparison to noninfected.

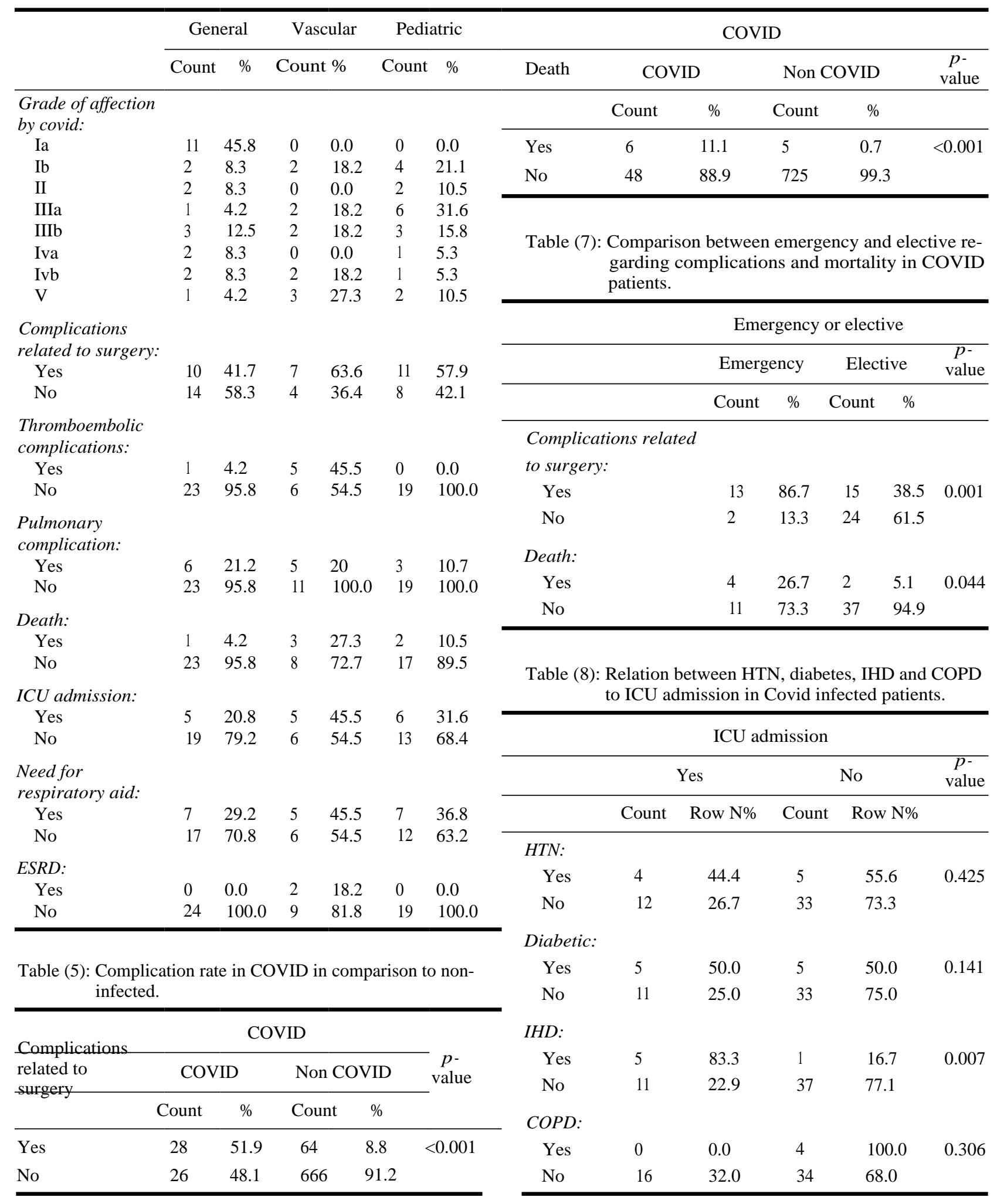


Table (9): Relation between HTN, diabetes, IHD and COPD to mortality in Covid infected patients.

\begin{tabular}{llllll}
\hline & \multicolumn{5}{c}{ Death } \\
\cline { 2 - 5 } & \multicolumn{2}{c}{ Yes } & \multicolumn{2}{c}{ No } & $\begin{array}{c}p \text { - } \\
\text { value }\end{array}$ \\
\cline { 2 - 5 } & Count & Row N\% & Count & Row N\% & \\
\hline HTN: & & & & & \\
Yes & 3 & 33.3 & 6 & 66.7 & 0.051 \\
No & 3 & 6.7 & 42 & 93.3 & \\
Diabetic: & & & & & \\
Yes & 2 & 20.0 & 8 & 80.0 & 0.306 \\
No & 4 & 9.1 & 40 & 90.9 & \\
IHD: & & & & & \\
Yes & 3 & 50.0 & 3 & 50.0 & 0.014 \\
No & 3 & 6.3 & 45 & 93.8 & \\
COPD: & & & & & \\
Yes & 0 & 0.0 & 4 & 100.0 & 1 \\
No & 6 & 12.0 & 44 & 88.0 & \\
\hline
\end{tabular}

Table (10): Surgical complications in Covid patients with congenital heart disease.

\begin{tabular}{|c|c|c|c|c|c|}
\hline \multirow{3}{*}{$\begin{array}{l}\text { Congenital } \\
\text { heart } \\
\text { disease }\end{array}$} & \multicolumn{4}{|c|}{ Complications related to surgery } & \multirow{3}{*}{$\begin{array}{c}p- \\
\text { value }\end{array}$} \\
\hline & \multicolumn{2}{|r|}{ Yes } & \multicolumn{2}{|r|}{ No } & \\
\hline & Count & Row N \% & Count & Row N \% & \\
\hline Diseased & 2 & 66.7 & 1 & 33.3 & 1 \\
\hline Normal & 9 & 56.3 & 7 & 43.8 & \\
\hline
\end{tabular}

Table (11): ICU admission in covid patients with congenital heart disease.

\begin{tabular}{lccccc}
\hline \multirow{2}{*}{$\begin{array}{l}\text { Congenital } \\
\text { heart } \\
\text { disease }\end{array}$} & \multicolumn{4}{c}{ Yes } & \multicolumn{2}{c}{ No } & \multirow{2}{c}{$\begin{array}{c}\text { I- } \\
\text { value }\end{array}$} \\
\cline { 2 - 5 } \cline { 4 - 5 } & Count & Row N \% & Count & Row N \% & \\
\hline Diseased & 1 & 33.3 & 2 & 66.7 & 1 \\
Normal & 5 & 31.3 & 11 & 68.8 & \\
\hline
\end{tabular}

Table (12): Mortalty in in covid patients with congenital heart disease.

\begin{tabular}{lccccc}
\hline \multirow{2}{*}{$\begin{array}{l}\text { Congenital } \\
\text { heart } \\
\text { disease }\end{array}$} & \multicolumn{4}{c}{ Yes } & \multicolumn{3}{c}{ No } & $\begin{array}{c}p \text { - } \\
\text { value }\end{array}$ \\
\cline { 2 - 5 } \cline { 4 - 6 } & Count & Row N \% & Count & Row N \% & \\
\hline $\begin{array}{l}\text { Diseased } \\
\text { Normal }\end{array}$ & 2 & 66.7 & 1 & 33.3 & 0.018 \\
\hline
\end{tabular}

\section{Discussion}

SARS-CoV-2 was first detected in Wuhan, China, in December 2019 and then spread worldwide, with the World Health Organization certified it as a pandemic on March 11, 2020. Significant data are accumulating on COVID-19, the disease caused by it, from many different perspectives [7]

At the 18 th of March 2020 the government of Egypt announced general closure in all governmental and private agencies for the fear of spread of corona virus among Egyptian people, there was also special policies for dealing with governmental health systems in all sides of the country as all elective cases were postponed and only emergency cases and cancer patients were admitted for surgery. In July was the regression of the $1{ }^{\text {st }}$ wave in Egypt occurred. So, newer regulations were decided to begin for scheduling the waiting listed patients with extreme precautions such as pre-operative covid 19 symptoms check list, CBC, and chest CT scan and exclusion of suspected cases except in emergency conditions suspected patients were operated upon in isolation buildings in the hospital for safety of the staff and other patients. We did rely more on CBC and CT chest in suspicion of Covid 19 infection as the nasal and throat swab PCR sensitivity had a percentage of false negatives, also because the result of swab takes from 24-48 hours our policy found CT changes and CBC may be a more fast and reliable way.

In this study, patients were treated by different subspecialties (Pediaetric, General, and Vascular Surgery) in a single hospital, Al-Zahraa University Hospital, Cairo, Egypt. 54 Covid 19 patients were identified and included in the study, which are $6.88 \%$ of all patients and; 24 patients in surgery $(3.01 \%) 11$ in vascular surgery $(1.4 \%)$ and 19 patients in pediatric surgery $(2.4 \%)$. Only 15 $(27.77 \%)$ patients were emergency cases. The 39 (72\%) patients who were elective $20(37 \%)$ were postponed and reoperated after passing the infection (Table 1).

The 54 surgical patients screened for SARSCoV-2 infection during the study period were evaluated, positive findings from CT chest, CBC and CRP except 3 patients were diagnosed by PCR, the same information was reported by Borghashi et al. $[\mathbf{8 , 9}]$.

Our significant increase in mortality and ICU admission rate in Covid 19 patients was similar to (Kraft et al.) [10] who experienced mortality rate of $40 \%$ for those who was in urgent need of surgery from Covid patients, however both studies has small sample sizes.

(Challine et al. [11]) also had similar results as he found higher rate of post-operative complications in Covid 19 group with a significant increase in 
complications even in a symptomatic patients, this study was conducted in a larger sample size 573 infected patients with Covid $19 p$-value $<.001$ in mortality and $<.001$ in overall morbidity.

Commonly vascular affection required hospital admission and surgical therapy, especially in COVID patients. Previously reported worldwide experiences emphasised the link between SARS-CoV2 infection and microvascular inflammation, distal vasculitis, and the prothrombotic state. These data seemed to be related to the inflammatory cytokine storm contributing to the pro-coagulative and proadhesive state of dysfunctional endothelium [3] Moreover, abnormal coagulation parameters are usually associated with poor prognosis in COVID19 patients [12].

In this study 8 types of elective operations and 3 of emergency operation in the Vascular Surgery Department that would be carried out during the COVID 19 pandemic: Limb salvage surgery (3 bypass and 2 endovascular approach), 2 primary repair of aneurysm, 1 major amputations and 2 salvage of arteriovenous fistula. Thrombotic complications were significantly associated with COVID-19 (Table 2). Recent articles have highlighted the possible prothrombotic state of patients with COVID-19 [13].

Tan et al., [14] described 6 types of elective operations that would be carried out during the COVID19 pandemic: Limb salvage surgery (bypass or endovascular approach), aortic aneurysm surgery, vascular oncology surgery, major and minor amputations, creation, and salvage of arteriovenous fistula.

In our study 16 patients $(66.4 \%)$ had a postoperative complication $<3$ according to, and 8 patients $(33.6 \%)$ had a post-operative 3 , (Table ). Complications related to surgery in Covid affected patients there were $28(51.9 \%), 10$ out of 24 in General Surgery (41.7\%), 7 out of 11 in Vascular Surgery patients (63.6\%) and 11 out of 19 in Pediatric Surgery (57\%), significant increase in surgery related complications in Covid infected patients in comparison to non-infected patients $p$-value 0.001 . No significant relationship between surgery related complications and the presence of associated chronic disease in Covid infected patients. Pulmonary complications were the most frequent, as reported by others $[7,15]$.

Aminian et al., reported that 2 of 3 patients died as a consequence of post-operative fever and pulmonary complications after uneventful elective surgery at the beginning of the COVID-19 outbreak in Iran [5].

A report published from Lombardy with 116 patients treated for several vascular pathologies demonstrated a mortality rate of $2.6 \%$. Which is much less than our study that might be because of bad general condition of our patients [16] (De Angelis et al., 2021).

In paediatric patients the rate of complication related to surgery $57.9 \%$ in relation to non Covid cases also the rate of operative complication differ in emergency case which the rate of complication is higher. Also Pelizzo G., et al., [17] find the high pre-operative and post-operative complication high rate than in normal cases.

In our study postponing of elective case in pediatric patients was mandatory and preparation of cases to surgery improvre post-operative outcome the same finding of study done by Hua $\mathrm{Z}$., et al., [18].

Mortality rate among children associated with congenital heart disease in urgent cases is confirmed by Johance et al., [19] and his recommendation to decrease this ratio is good pre-operative assessment, evaluation of infection grading then intubation and extubation of patient must be in isolated environment to decrease the rate of re infection. And also recommended post-operative ICU admission to evaluate progression of cases.

Rahul, et al., [20] dealing with Covid 19 pandemic infection by postponing all elective cases and dealing only with emergency cases and neonatal congenital anomalies with highly pre-operative preparation and caring for all cases needed surgical intervention to decrease morbidity and mortality rates.

\section{Conclusion:}

There is significant effect for Covid 19 pandemic on the outcome of surgical work in surgery related complications, ICU admission and even mortality rate more in emergency cases, cases with ischemic heart disease and congenital heart disease however, no direct relation in our study between bad surgical outcomes and presence of other chronic diseases.

Study limitations: Our study was limited by relatively small sample size, lack of availability of PCR for nasal swab of Covid 19.

Conflict of interst: No conflict of interst. 


\section{References}

1- WILDER-SMITH A., CHIEW C.J. and LEE V.J.: Can we contain the COVID-19 outbreak with the same measures as for SARS? Lancet Infect. Dis., 20 (5): e102-e107, 2020.

2- World Health Organization. Coronavirus Disease (COVID19). Situation Report. Aviruse/situationreports/20200610 covid-19-sitrep-142.pdf?sfvrsn=180898cd_6.

3- World Health Organization: Coronavirus Disease 2019 (COVID-19) Situation Report - 209. WHO, Geneva, 2020.

4- AMODEO G., BUGADA D., FRANCHI S., et al.: Immune function aftermajor surgical interventions: The effect of post-operative pain treatment. J. Pain Res., 11: 1297-305, 2018.

5- AMINIAN A., SAFARI S., RAZEGHIAN-JAHROMI A., GHORBANI M. and DELANEY C.P.: COVID-19 outbreak and surgical practice: Unexpected fatality in perioperative period. Ann. Surg., 272 (1): e27-9, 2020.

6- CHEN X., LIU Y., GONG Y., et al.: Perioperative management of patients infected with the novel coronavirus: Recommendation from the joint task force of the Chinese society of anesthesiology and the Chinese association of anesthesiologists. Anesthesiology, 132 (6): 1307-16, 2020.

7- LEI S., JIANG F., SU W., et al.: Clinical characteristics and outcomes of patients undergoing surgeries during the incubation period of COVID-19 infection. E ClinicalMedicine, 0 (0): 100331. doi:10.1016/j.eclinm.2020. 100331, 2020.

8- BORGHESI A. and MAROLDI R.: COVID-19 outbreak in Italy: Experimental chest X-ray scoring system for quantifying and monitoring disease progression. Radiol. Med., 125 (5): 509-13, 2020.

9- BORGHESI A., ZIGLIANI A., MASCIULLO R., et al.: Radiographic severity index in COVID-19 pneumonia: Relationship to age and sex in 783 Italian patients. Radiol. Med., 125 (5): 461-4, 2020.

10- KRAFT, MIQUEL, GIANLUCA PELLINO, MARIONA JOFRA, MARIA SORRIBAS, ALEJANDRO SOLÍS-PE NA, SEBASTIANO BIONDO and ELOY ESPÍNBASANY: "Incidence, Features, Outcome and Impact on Health System of de-Novo Abdominal Surgical Diseases in Patients Admitted with COVID-19, 2020.

11- CHALLINE, ALEXANDRE, BERTRAND DOUS SET, NICOLA DE'ANGELIS, H. LEF EVRE, YANN PARC, SANDRINE KATSAHIAN and ANDREA LAZZATI: "Impact of Coronavirus Disease 2019 (COVID-19) Lockdown on in-Hospital Mortality and Surgical Activity in Elective Digestive Resections: A Nationwide Cohort Analysis, 2020.
12- NENCIONI A., TRZECIAK S. and SHAPIRO N.I.: The microcirculation as a diagnostic and therapeutic target in sepsis. Intern. Emerg. Med., 4: 413e8, 2009.

13- KLOK F.A., KRUIP M.J.H.A., VAN DER MEER N.J.M., et al.: Incidence of thrombotic complications in critically ill ICU patients with COVID-19. Thromb. Res., 191145147. -147. doi: 10, 2020.

14- TAN L.G.W., CHANDRASEKAR S., LO Z.J., et al.: Early experience in the COVID-19 pandemic from a vascular surgery unit in a Singapore tertiary hospital. J. Vasc. Surg., 17: 12-5, 2020.

15- LI Y.K., PENG S., LI L.Q., et al.: Clinical and transmission characteristics of COVID-19 retrospective study of 25 cases from a single thoracic Surgery Department. Curr. Med. Sci., 2020.

16- ANGELIS, ELENA De, STEFANO RENZETTI, MARIALUISA VOLTA, FRANCESCO DONATO, STEFANO CALZA, DONATELLA PLACIDI, ROBERTO G. LUCCHINI, and MATTEO ROTA: "COVID-19 Incidence and Mortality in Lombardy, Italy: An Ecological Study on the Role of Air Pollution, Meteorological Factors, Demographic and Socioeconomic Variables." Environmental Research 195 (April): 110777. https://doi.org/ 10. 10 16/j.envres.2021.110777, 2021.

17- The Challenges of a Children's Hospital during the COVID19 Pandemic: The Pediatric Surgeon's Point of View Gloria Pelizzo 1, 2, *, Sara Costanzo 1, Luciano Maestri 1, Giorgio Giuseppe Orlando Selvaggio 1, Andrea Pansini 1, Gian Vincenzo Zuccotti 2, 3, Elena Zoia 4, Giuseppe De Filippis 5, Alessandro Visconti 5 and Valeria Calcaterra 3, 6 Pediatr. Rep., 12: 114-23; doi:10.3390/pediatric 12030025, 2020.

18- HUA ZHENG, HARRY, HEBERT ATHANASIA CHATZIPE, WEIHUA MEG, et al.: Pre-operative mangment of patients with suspected or confirmed covid 19: Review and recommendation for pre-operative mangment from a retrospective cohart study. British Journal of Anaesthesia, 125 (6): 895e911, 2020.

19- WALI R. JOHNSON, BARBARA SHULTZ, CHRISTOPHER T. WOOTTEN, JAY C. WELLONS and JEFFREY S. UPPERMAN: Pediatric Peri-Operative Care in the COVID-19 Era; SURGICAL INFECTIONS Volume 21, Number 5, 202.

20- Pediatric surgery during coronavirus disease lockdown: Multicenter experience from North India, Sandip Kumar Rahul1, Manish Kumar Gupta2, Digamber Chaubey1, Deepak Kumar3, Rupesh Keshri1, Vijayendra Kumar1, Vijai Datta Upadhyaya4* Formosan Journal of Surgery | Volume 53 | Issue 6 | November-December, 2020. 


\section{تآثير عدوى كورونا على النتائج الجراحية (خبرة من مركز فردى النتائ الجرئ}

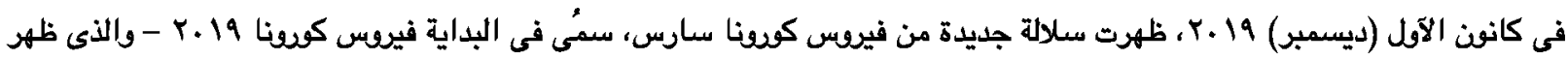

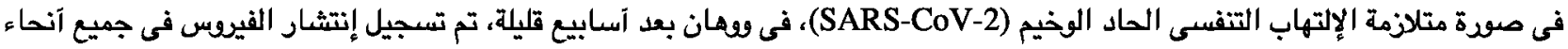

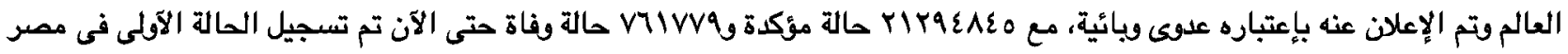

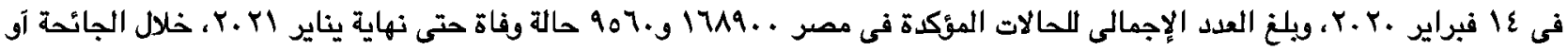

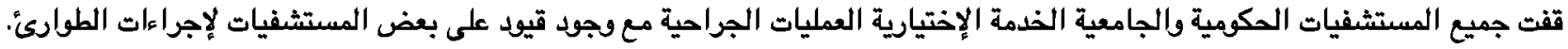

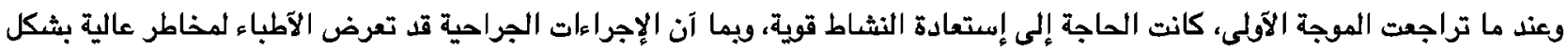

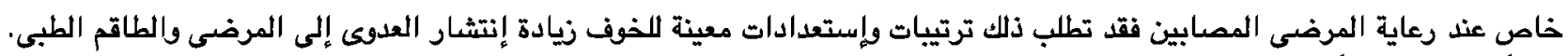

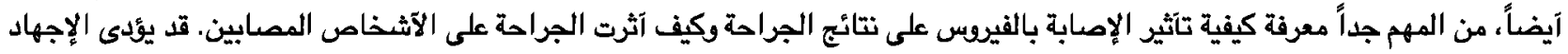

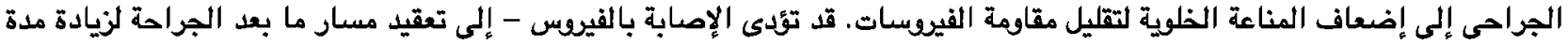

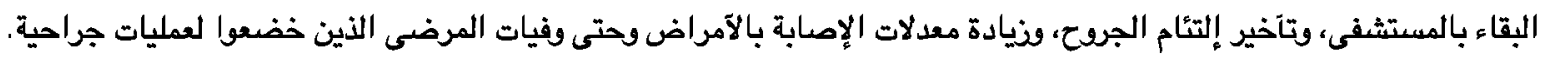

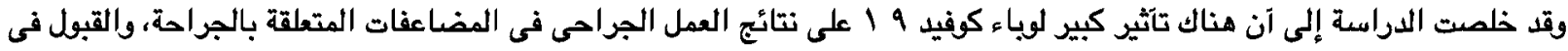
وحدة العناية المركزة وحتى معدل الوفيات أكثر فى حالات الطوارئ، وحالات آمراض القلب القيل الإقفارية وآمراض القلب الخلقية. 